\title{
How precisely can we anticipate seismic intensities? A study of uncertainty of anticipated seismic intensities for the Earthquake Early Warning method in Japan
}

\author{
Mitsuyuki Hoshiba ${ }^{1}$, Kazuo Ohtake ${ }^{1}$, Kazuhiro Iwakiri ${ }^{1}$, Tamotsu Aketagawa ${ }^{2 *}$, \\ Hiromitsu Nakamura ${ }^{3}$, and Shunroku Yamamoto ${ }^{4}$ \\ ${ }^{1}$ Meteorological Research Institute, Nagamine 1-1, Tsukuba, 305-0052, Japan \\ ${ }^{2}$ Japan Meteorological Agency, Ohte-machi 1-3-4, Chiyoda, Tokyo, 100-8122, Japan \\ ${ }^{3}$ National Research Institute for Earth Science and Disaster Prevention, Tennodai, Tsukuba, 305-0006, Japan \\ ${ }^{4}$ Railway Technical Research Institute, Hikari-cho 2-8-38, Kokubunji, Tokyo, 185-8540, Japan
}

(Received July 27, 2009; Revised July 21, 2010; Accepted July 22, 2010; Online published October 28, 2010)

\begin{abstract}
The precise calculation of anticipated seismic intensity is an important component of Earthquake Early Warning (EEW) procedures. The EEW method adopted by the Japan Meteorological Agency (JMA) uses event magnitude, hypocentral distance, and site amplification factor for this calculation, in which the site amplification factor is represented by a single scalar without consideration of spectrum contents. Even when two earthquakes occur at the same location with the same magnitude, their observed distributions of seismic intensity are not always the same. And even at adjacent measurement stations, the interstation difference in seismic intensity of one earthquake is not always the same as that of another earthquake. To evaluate these expected uncertainties in the current JMA EEW method, we analyzed the distribution of recorded seismic intensities from adjacent earthquakes and also compared the intensities at adjacent observation sites. The uncertainties are 0.29 JMA intensity units when the JMA magnitude is used as an index of source factor and 0.22 when the average of the observed seismic intensities is used. The uncertainties are 0.21 when site amplification factor is represented by single scalar value. These results may indicate the intrinsic precision limits of anticipated seismic intensities in the current JMA EEW method.
\end{abstract}

Key words: Earthquake Early Warning, seismic intensity, prediction of ground motion, uncertainty.

\section{Introduction}

Earthquake Early Warning (EEW) systems have been researched and developed in Mexico, the USA, Taiwan, Italy, Turkey, and other countries (e.g., Espinosa Aranda et al., 1995; Alcik et al., 2009; Allen et al., 2009; Hsiao et al., 2009; Zollo et al., 2009). EEW systems aid in mitigating an earthquake disaster by giving people enough time to take appropriate safety measures in advance of strong shaking. A practical nationwide EEW began in Japan and became fully operational in October 2007 by the Japan Meteorological Agency (JMA) (Hoshiba et al., 2008; Kamigaichi et al., 2009). In the JMA method, the locations of hypocenters and magnitudes of earthquakes are determined as quickly as possible using real-time data collected from stations near the hypocenter, and the distribution of the anticipated seismic intensities is rapidly estimated. If anticipated seismic intensities surpass a threshold value, the earthquake information and appropriate warnings are deliv-

\footnotetext{
*Present address: Hot Spring Research Institute, Iriuda 586, Odawara, Kanagawa, 250-0031, Japan.

Copyright (c) The Society of Geomagnetism and Earth, Planetary and Space Sciences (SGEPSS); The Seismological Society of Japan; The Volcanological Society of Japan; The Geodetic Society of Japan; The Japanese Society for Planetary Sciences; TERRAPUB.
}

doi:10.5047/eps.2010.07.013 ered immediately to governmental offices, representatives from various industries, member of the news media, and various individuals before strong ground shaking reaches them. The precise anticipation of seismic intensities is, therefore, an important component of the EEW system. The EEW algorithm should be able to predict the seismic intensity not only quickly but also precisely.

Predictions of seismic ground motion usually consider a source factor, a path factor, and a site amplification factor. The general function form commonly used for the prediction of seismic ground motion is

$$
A=S * f_{1}\left(R, D_{\mathrm{s}}\right) * G,
$$

where $A$ is a ground motion parameter (e.g., peak ground acceleration, peak ground velocity, spectrum amplitude, or seismic intensity), $f_{1}\left(R, D_{\mathrm{s}}\right)$ represents the attenuation relation depending on distance from the source $R$ and focal depth $D_{\mathrm{s}}$, and $S$ and $G$ are factors for source characteristics and site amplification, respectively. A more sophisticated form is

$$
A=S * f_{2}\left(\lambda_{\mathrm{g}}, \phi_{\mathrm{g}}, \lambda_{\mathrm{s}}, \phi_{\mathrm{s}}, D_{\mathrm{s}}\right) * G
$$

which incorporates the effect of three-dimensional (3D) attenuation structure, where $\lambda_{\mathrm{g}}, \phi_{\mathrm{g}}$ represent the site location and $\lambda_{\mathrm{s}}, \phi_{\mathrm{s}}$ the epicentral location. 


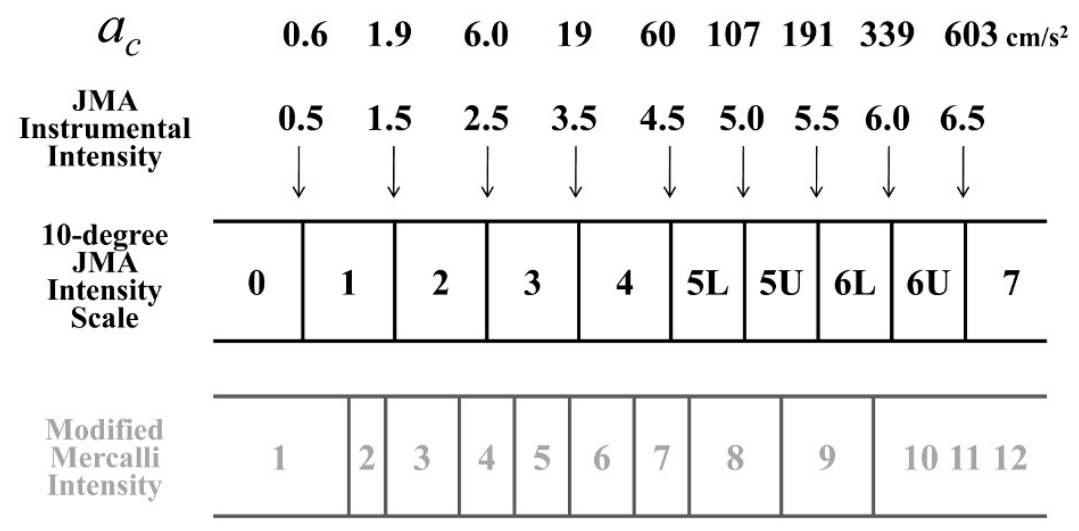

Fig. 1. Relation of $a_{\mathrm{c}}$ in Eq. (3), JMA instrumental seismic intensity, and 10-degree JMA intensity scale as well as the approximate relation of the JMA intensity scale and Modified Mercalli scale. "L" and "U" on 5 and 6 of the 10-degree JMA scale indicate "lower" and "upper" delineations.

JMA currently uses formulation (1) in its EEW system. The technique adopted for the rapid determination of the hypocenter and magnitude is based on several methods developed by JMA and the Railway Technical Research Institute, and also by the National Research Institute for Earth Science and Disaster Prevention (NIED) (Odaka et al., 2003; Kamigaichi, 2004; Tsukada et al., 2004; Horiuchi et al., 2005; Nakamura et al., 2009) using waveform data from the JMA network and from NIED's Hi-net network. Anticipated seismic intensity is based on the empirical methods of Si and Midorikawa (1999), Matsuoka and Midorikawa (1994), and Midorikawa et al. (1999), which are based on the hypocentral distance, focal depth, magnitude, and site amplification factor as represented in (1). Here, the source factor $S$ and site amplification factor $G$ are each represented by single scalars, without consideration of spectrum contents.

The uncertainty of ground motion predictions and the limits of that uncertainty have been considered by many authors (e.g., Douglas and Smit, 2001; Ikeura and Noda, 2005; Atkinson, 2006; Bragato, 2008; Morikawa et al., 2008; Strasser et al., 2009). Most of these studies relied on (1). Considerations based on (2) have not yet well researched.

In this paper, we investigate the precision of anticipated seismic intensities using recorded seismic intensity data based on (2). We also consider how much uncertainty should be expected when the source factor $S$ and site amplification factor $G$ are represented by scalars, provided that the hypocenter and magnitude are determined precisely.

\section{Data}

In Japan, the JMA intensity scale is widely used for seismic intensity. Since 1996 this scale has been based on instrumental measurements in which not only amplitude but also frequency and duration of the shaking are considered (Japan Meteorological Agency, 1996; Yamamoto et al., 2008). The definition of seismic intensity is

$$
I=2 \log _{10}\left(a_{\mathrm{c}}\right)+0.94
$$

where $I$ is JMA seismic intensity, and $a_{\mathrm{c}}$ is defined as the value satisfying the condition that total duration of $a(t)>$ $a_{\mathrm{c}}$ is $0.3 \mathrm{~s}$. Here, $a(t)$ is the time series of vector amplitude of the three components of band-pass filtered acceleration (measured in $\mathrm{cm} / \mathrm{s}^{2}$ ) in which the band-pass filter has a central frequency of $0.5 \mathrm{~Hz}$ to characterize damaging strong motion to wooden frame houses and felt shaking. The relations between $a_{\mathrm{c}}$, instrumental JMA intensity, and 10degree JMA intensity scale as well as the approximate relation of the JMA intensity scale and Modified Mercalli scale are given in Fig. 1. Since 1996 the highest observed seismic intensity has been 6.5, which was recorded at Kawaguchi, Niigata Prefecture during the 2004 Mid-Niigata Prefecture earthquake $(M=6.8$, focal depth $13 \mathrm{~km})$ in the source region $2.9 \mathrm{~km}$ from the epicenter, where many wooden houses collapsed (Japan Meteorological Agency, 2005). The peak ground acceleration of the unfiltered record was $1,722 \mathrm{~cm} / \mathrm{s}^{2}$ in the form of three-component vector amplitude at Kawaguchi.

Seismic intensity is currently (July 2010) measured at more than 4,000 sites throughout Japan by JMA, municipalities, and NIED. When an earthquake occurs, the instrumental seismic intensity data are transmitted to JMA and summarized. Our study used the JMA catalog of the instrumentally observed seismic intensities from 1996 to 2007. The catalog compiles the data of instrumental intensity $\geqq 0.5$.

For hypocenter and magnitude, we used the unified hypocenter catalog of JMA. JMA uses two methods to determine magnitudes: displacement magnitude for large earthquakes and velocity magnitude for small earthquakes (Japan Meteorological Agency, 2009). Displacement magnitude is determined from the maximum amplitude of displacement, and velocity magnitude is determined from the maximum amplitude of velocity. We used only those events whose magnitude was determined from displacement amplitudes in this analysis.

\section{Analysis}

3.1 Fluctuation of intensity when magnitude is used as the source factor

In the current method of the JMA EEW system, seismic intensity distributions of two earthquakes are expected to be the same if the earthquakes occur at the same location with the same magnitude. This expectation is based on $\lambda_{\mathrm{g}}, \phi_{\mathrm{g}}$, 
(a)

(1)

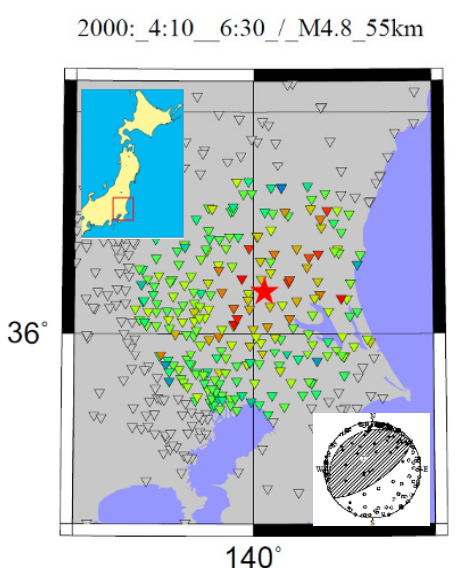

(2)

2005:12:28 18:46/M4.8 53km

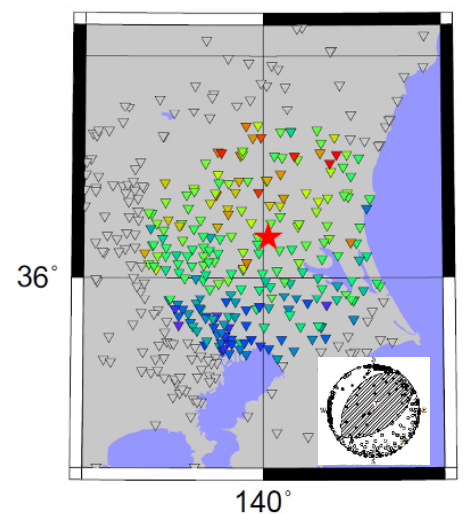

(b)
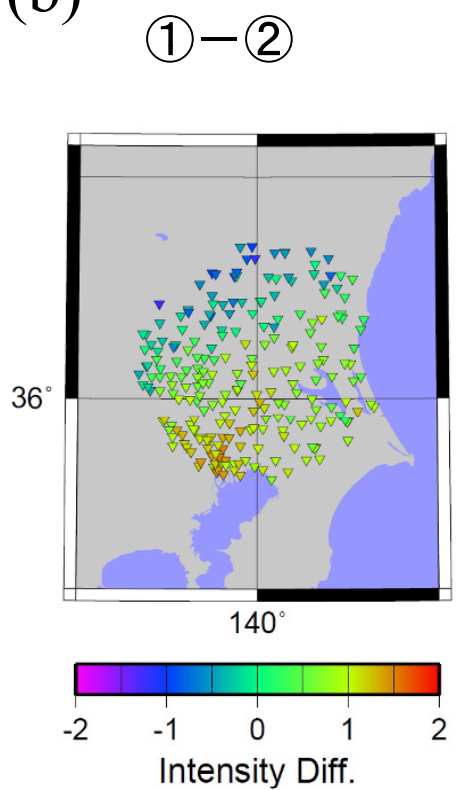

(c)

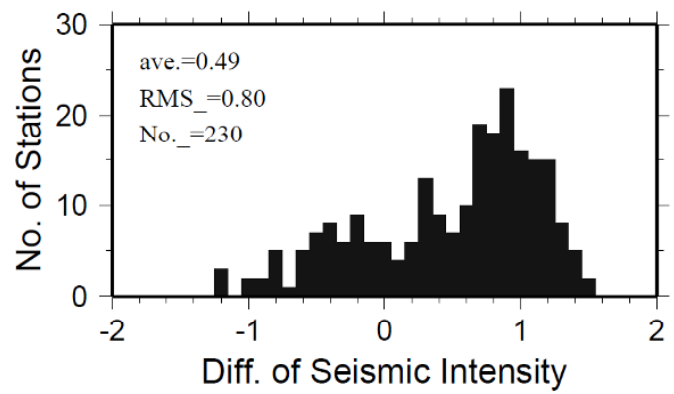

Fig. 2. (a) Observed seismic intensities of two nearly identical earthquakes in the Kanto region, Japan ( $M=4.8$, focal depth 55 and 53 km, respectively). The color of the triangles represents the observed seismic intensities; open triangles indicate stations not used in this analysis. Focal mechanisms obtained from polarity of $P$ waves are also shown. (b) Distribution of the difference in seismic intensity of the two earthquakes determined at the same stations, indicated by color of the symbols. (c) Histogram of the differences in seismic intensity shown in Fig. 2(b), with the average of the differences, RMS value, and number of data points shown at the upper left. A positive value means that the intensity of earthquake 1 is larger than that of earthquake 2; a negative value indicates the opposite.

and $G$ being common at each station and the assumption that $\lambda_{\mathrm{s}}, \phi_{\mathrm{s}}, D_{\mathrm{s}}$, and $S$ (represented by earthquake magnitude) are the same in Eq. (2). In the actual data, however, the distributions may not be always the same, and differences in intensity are observed. Figure 2(a) shows the distribution of seismic intensities of two $M=4.8$ earthquakes that occurred in almost the same location with focal depths only $2 \mathrm{~km}$ apart. Figure 2(b) shows the differences of their intensities, which are quite notable and include a directional dependence that may be due to the effect of rupture directivity. The effect of rupture directivity on wave amplitudes of $M=4-5$ earthquakes has been discussed by Hoshiba (2003). Figure 2(c) shows a histogram of the seismic intensity differences (intensity of earthquake 1 minus that of earthquake 2), which have a wide range for the event pair of Fig. 2(a). Therefore, even earthquakes at the same location and of the same magnitude can differ in their values and distribution of seismic intensity. We investigated these differences using pairs of adjacent earthquakes with the same magnitude.

For our analysis, we used earthquakes of magnitude 3.5 to 5.5 ; larger events were not used so as to avoid the effect of any inhomogeneous distribution of fault asperities on seismic intensity. We chose earthquake pairs on the condition that the JMA magnitudes were the same, the distance between their epicenters was $\leqq 5 \mathrm{~km}$, and their focal depths were $\leqq 5 \mathrm{~km}$ apart. As shown in Fig. 3, we exclude the data of a very small hypocentral distance to satisfy the assumption of the same path factor and also the data of a large hypocentral distance to avoid the influence of an artificial effect of unreported intensity (minimum value of reported intensity is 0.5 ). We used seismic intensity data from stations for which the hypocentral distance was greater than tenfold the distance between the hypocenters of the two earthquakes and smaller than the hypocentral distance of the station at which seismic intensity was $\leqq 0.6$ (that is, we exclude the data of the gray areas in Fig. 3). Of the qualifying earthquake pairs, we used only pairs with ten or more intensity data points. Earthquakes that met all of these criteria consisted of just 100 pairs. Figure 4 shows their locations.

As shown in Fig. 2(c), the difference of intensity in a 


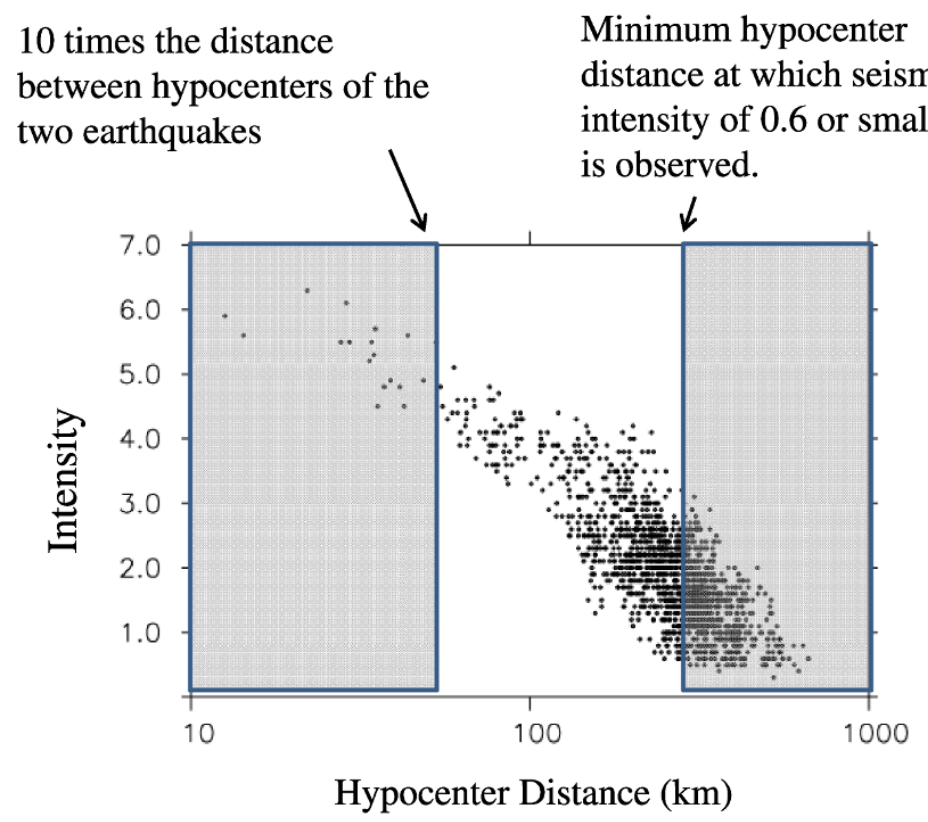

Fig. 3. Hypocentral distance range used for the analysis. Seismic intensity data were used from stations for which the hypocentral distance is more than tenfold the distance between the hypocenters of the two events and less than the hypocentral distance of the station at which seismic intensity was $\leq 0.6$. Intensity data of gray area are excluded in this analysis.

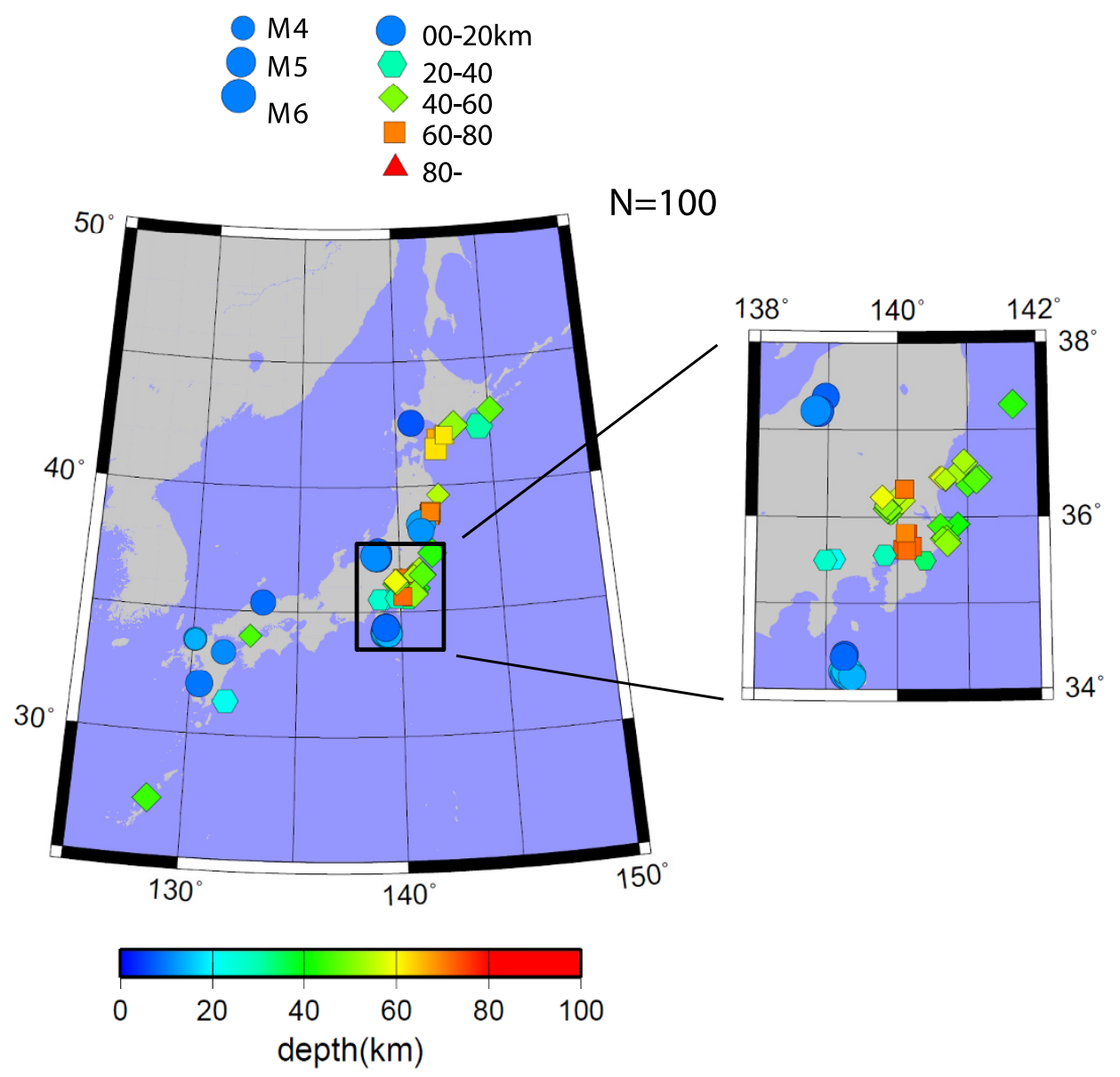

Fig. 4. Location of 100 pairs of earthquakes used in the analysis. For simplicity, one earthquake of the pairs is plotted in this figure. The size of the symbol represents the magnitude, and the difference in the symbol indicts the difference in the focal depth. 


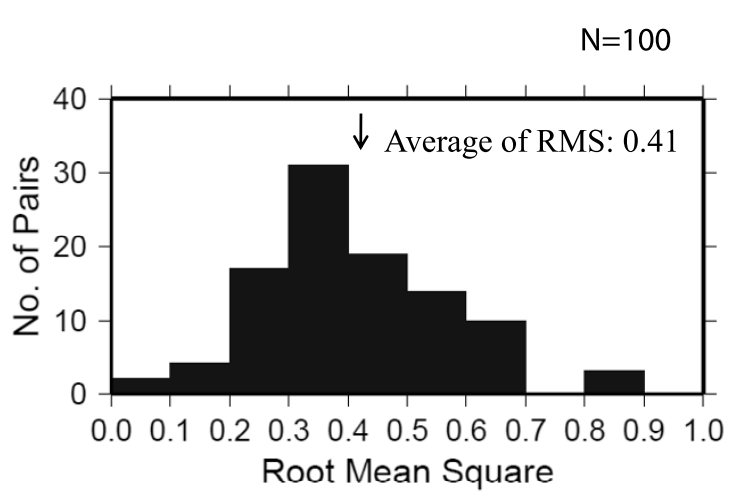

Fig. 5. Histogram of the RMS of the intensity difference for the 100 pairs of earthquakes. The average of the RMS determinations was 0.41 .

given earthquake pair ranges from -1.2 to 1.5 , and the root mean square (RMS) of the difference is 0.80 . Figure 5 is a histogram of RMS of the intensity differences for the 100 earthquake pairs. The average RMS is 0.41 , which can be taken as the uncertainty of seismic intensity that can be expected even when magnitude, path factor, and site amplification factor are the same.

\subsection{Fluctuation of intensity when average of intensity} is used as the source factor

As shown in Fig. 2(c), the histogram of RMS differences is not centered at zero, and a bias is apparent. This means that the JMA magnitude of an earthquake does not always represent the radiated energy from the source related to seismic intensity because JMA magnitude is determined from the displacement amplitude whereas seismic intensity is derived from filtered acceleration data, and the typical frequencies for magnitude determination and for seismic intensity determination may be different.

We can introduce the average of seismic intensity, instead of JMA magnitude, to represent source factor $S$ in Eq. (2). After substituting the average of the difference of the seismic intensities from the distribution, the RMS is reevaluated, as shown in Fig. 6. The difference of the average of seismic intensity is considered to be the difference of the source factor that determines the seismic intensities. Substituting the average of the difference of seismic intensities corresponds to an adjustment of the difference of the source factors. For this earthquake pair, the RMS changed from 0.80 to 0.64 . The histogram of the re-evaluated RMS for all 100 pairs is shown in Fig. 7; the average is 0.31 , which is a reduction of approximately $25 \%$ from that of the determinations using JMA magnitude. This reduction means that it may be possible to reduce the uncertainty of the anticipated seismic intensity when we use intensity itself instead of displacement amplitude for the source factor; it also means that the magnitude estimated from the intensity may be more appropriate than the displacement amplitude to calculate anticipated seismic intensities. The use of the intensity for estimates of magnitude, or "intensity magnitude," for EEW purposes has been proposed by Yamamoto et al. (2007, 2008).

In introducing the average of intensity differences as the

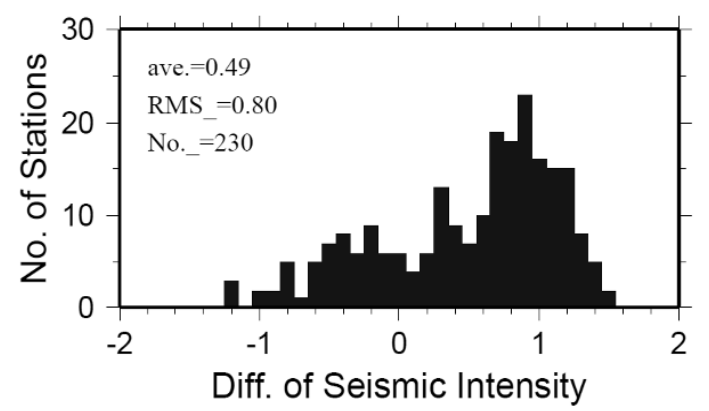

\section{$\mid \begin{aligned} & \text { Substituting the } \\ & \text { average }\end{aligned}$}

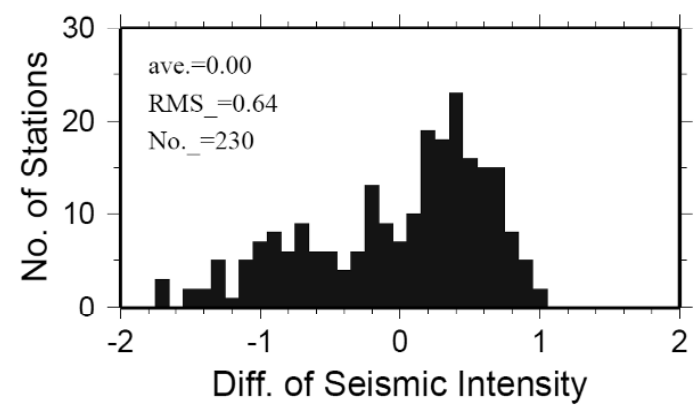

Fig. 6. Example of the procedure for correction of the source factor. (Top) Histogram of the differences in seismic intensity unadjusted as in Fig. 2(c); (bottom) after substituting the average of the difference of seismic intensity.

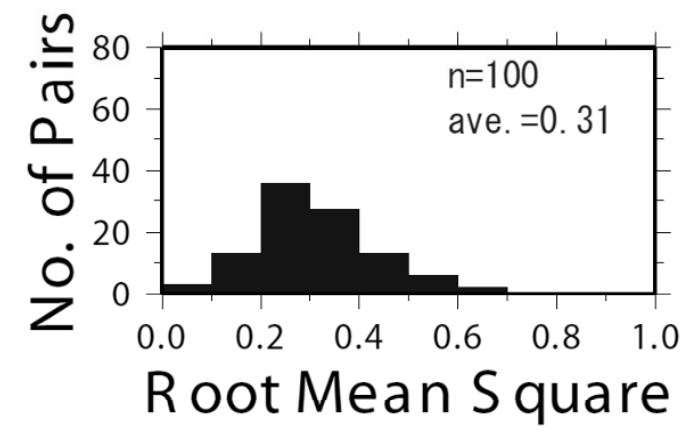

Fig. 7. Histogram of the RMS of the intensity difference for the 100 earthquake pairs after substituting the average of the difference of seismic intensity at each pair as the source factor. The average RMS was 0.31 .

source factor, it is no longer necessary to use earthquake pairs having the same JMA magnitude. Figure 8 shows the distribution of RMS values for various cases of magnitude difference $(\Delta M=0.0-0.5)$, where the average of RMS for $\Delta M \leq 0.5$ is 0.33 for 833 pairs. This distribution demonstrates that the dependence of the average RMS on the magnitude difference is weak.

The RMS of three pairs is larger than 0.8 , as shown in Fig. 8 (bottom), which means that there is quite a large variation of seismic intensity in three of the 833 cases (approximately $0.4 \%$ ) even after correcting for the difference of the source factor. This figure indicates that we should expect a large uncertainty in the intensity anticipation for $0.4 \%$ of 

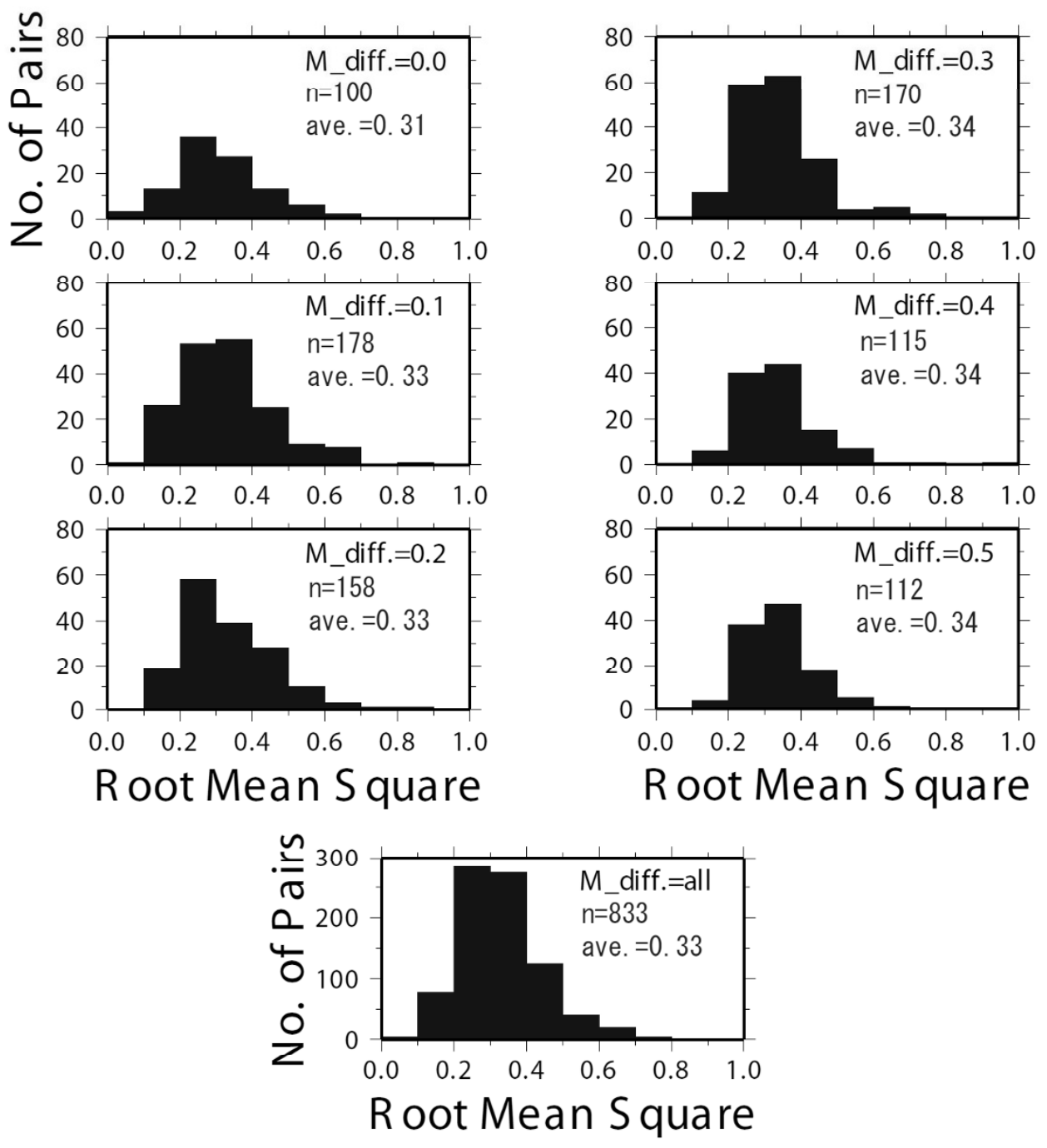

Fig. 8. Distribution of the RMS (after substituting the average of the difference of seismic intensity as the source factor) for various cases of magnitude difference $(\Delta M=0.0,0.1,0.2,0.3,0.4$, and 0.5$)$. Numbers of data points and the average of the RMS are shown. The bottom panel summarizes the upper six panels.

Table 1. The dependence of the RMS on the criteria for the selection of the earthquake pairs. The RMS is evaluated for difference criteria of the distance between the epicenters.

\begin{tabular}{ccc}
\hline $\begin{array}{c}\text { Distance between the epicenters for } \\
\text { the selection of the earthquake pair }\end{array}$ & RMS & $\begin{array}{c}\text { Number of pairs used } \\
\text { for estimation of RMS }\end{array}$ \\
\hline$\leq 5 \mathrm{~km}$ & 0.33 & 833 \\
$\leq 10 \mathrm{~km}$ & 0.34 & 1,019 \\
$\leq 15 \mathrm{~km}$ & 0.34 & 1,033 \\
\hline
\end{tabular}

the events.

In the above analysis, we used $5 \mathrm{~km}$ for the maximum distance between the epicenters for the selection of earthquake pairs. We estimate the RMS using other criteria in addition to $5 \mathrm{~km}$ and summarize the results in Table 1 . The dependence of the RMS on the criteria is small, and the result is not influenced by the criteria for the selection of earthquake pairs. The reason why the number of pairs does not increases with increasing the distance is that more data are excluded with increasing distance and pairs therefore do not satisfy the condition of ten or more intensity data points (Fig. 3).

Fluctuation of the intensity, that is, the RMS, may depend on the magnitude. Figure 9 is a histogram of magnitudes of the 100 earthquake pairs having the same magnitude. The 100 pairs were divided into three groups according to their magnitude $(M=3.6-4.2,4.3-4.6$, and 4.7-5.4), and their respective distributions of RMS were estimated (Fig. 9). The average of RMS increased with increasing magnitude, but the dependence of average RMS on magnitude was weak. The increase in RMS with increasing magnitude may be due to the effect of an inhomogeneous distribution of asperity or to the complicated source process of relatively large earthquakes.

\subsection{Fluctuation due to the site amplification factor}

In the calculation of anticipated seismic intensity, it is assumed that the difference in seismic intensities at two adjacent observation sites is almost independent of earthquakes and a constant. In Eq. (2), $S$ is common and $f_{2}\left(\lambda_{\mathrm{g}}, \phi_{\mathrm{g}}, \lambda_{\mathrm{s}}, \phi_{\mathrm{s}}, D_{\mathrm{s}}\right)$ is assumed to be the same, so that the difference in seismic intensity is controlled by $G$ indepen- 

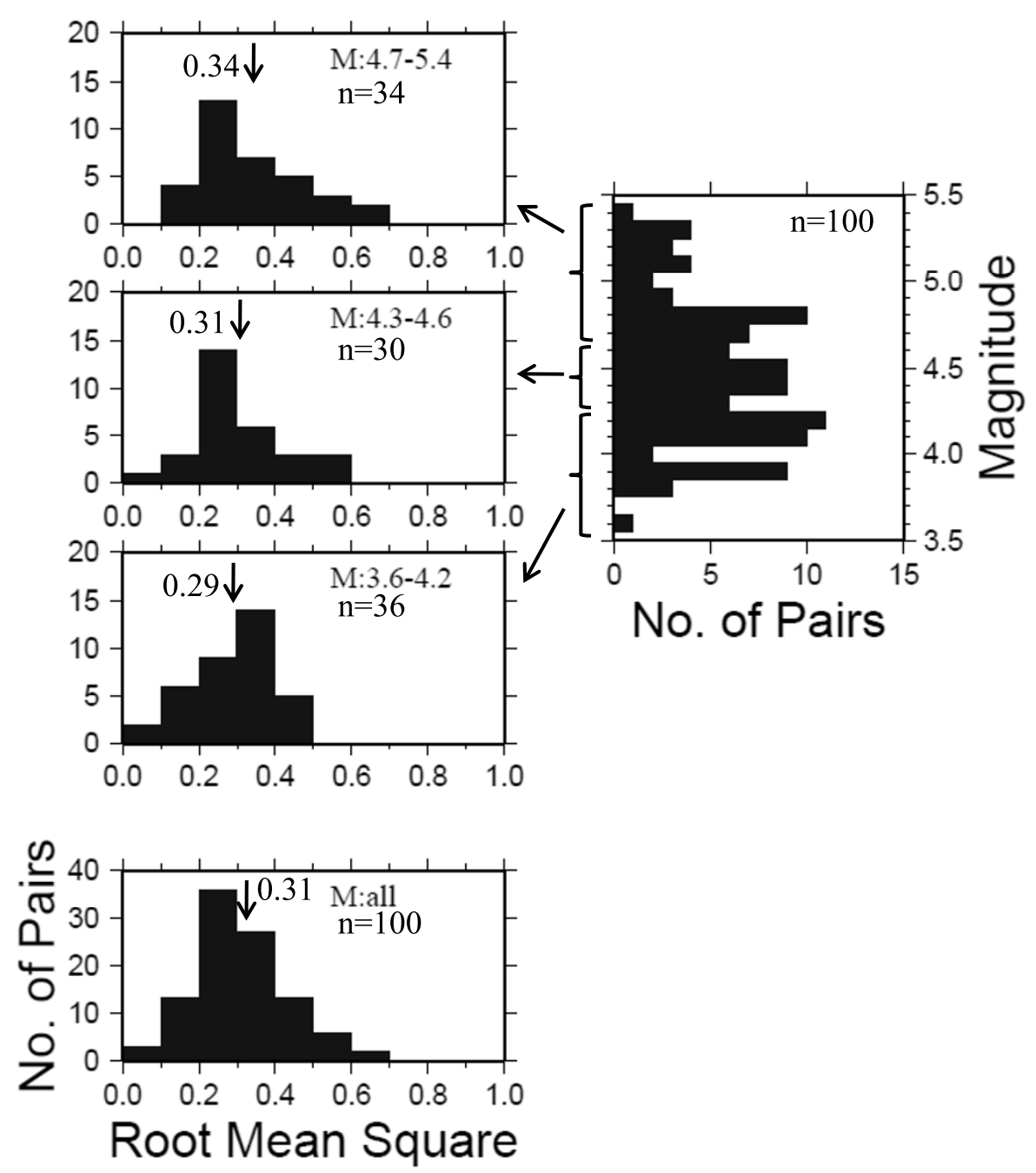

Fig. 9. Histogram of the RMS of the intensity differences for the 100 earthquake pairs (as in Fig. 7), separated into three magnitude categories.

dent of earthquakes when $G$ is represented by single scalar value. For example, if the difference in seismic intensities at two adjacent sites is 0.5 for one earthquake, it should be 0.5 for another earthquake. The actual data, however, contradict that assumption. Figure 10 shows examples of the variation in seismic intensity differences measured at two pairs of observation sites, one in which the two sites are $0.9 \mathrm{~km}$ apart (Fig. 10(a)) and another in which they are $1.0 \mathrm{~km}$ apart (Fig. 10(b)). The shift of the center of the distribution away from zero is considered to be the difference in the site amplification factors of the two sites. The effects of site amplification factors are taken into account in the current EEW procedure for anticipated seismic intensity. It should be noted here that the variation of the difference in the seismic intensity is recognized. The difference in intensity ranges from -1.0 to 0.9 for the case of Fig. 10(a) and from -1.8 to 0.3 for Fig. 10(b). The variation introduces uncertainty into the anticipated seismic intensities.

We investigated how large a variation of intensity difference is observed in real data from two adjacent observation sites. For our analysis, we chose the site pairs on the con- dition that the distance between the sites was $\leqq 5 \mathrm{~km}$, and we again used earthquakes of magnitude of $M=3.5$ to 5.5 and applied the same criteria given in Section 3.1 for seismic intensities. This procedure yielded 791 pairs of station sites.

The standard deviation, that is, the RMS difference from the average, was 0.52 for the site pair of Fig. 10(a) and 0.40 for the site pair of Fig. 10(b). Figure 11 is the histogram of the standard deviations of the intensity differences for the 791 pairs. The average of these standard deviations was 0.29 , which is an indication of the expected differences of seismic intensity even at adjacent sites. This average suggests that we should expect such a fluctuation in seismic intensity for each observation site even if the source factor and path factor are the same-when the site amplification factor is represented by a single scalar value.

\section{Conclusion}

We investigated how precisely seismic intensities are forecasted in EEW calculations and what degree of uncertainty should be expected in the anticipated intensities. The 
(a)
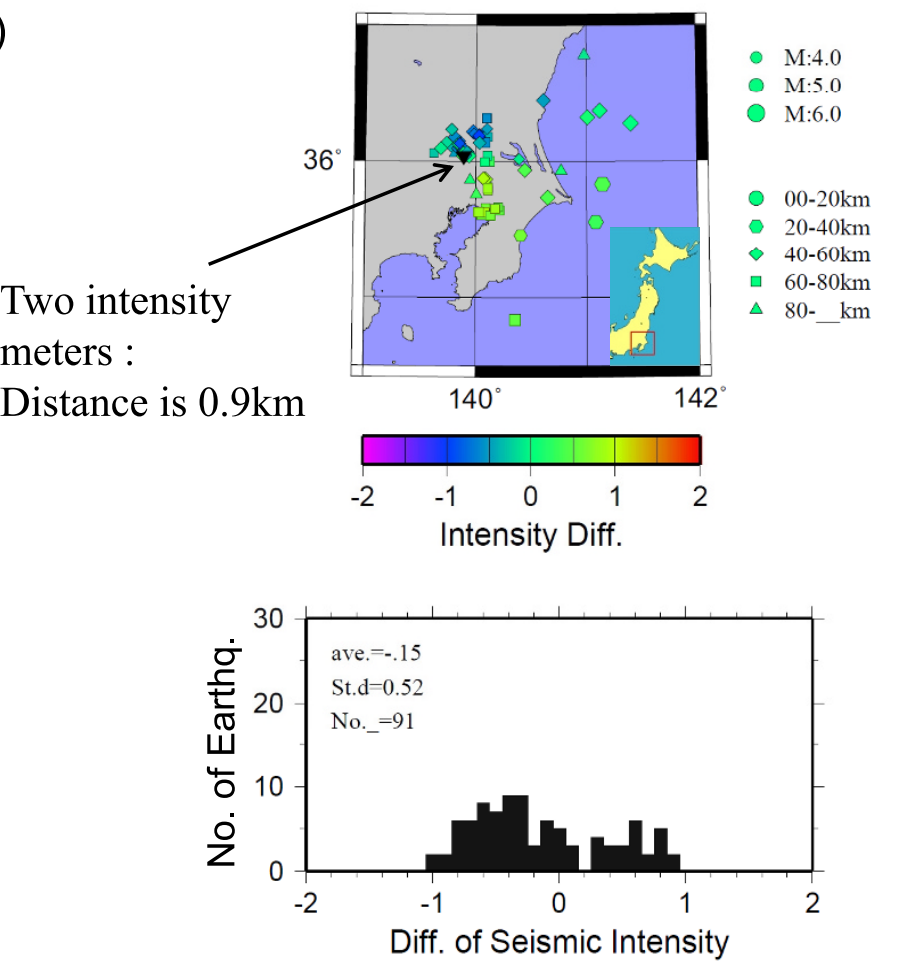

(b)
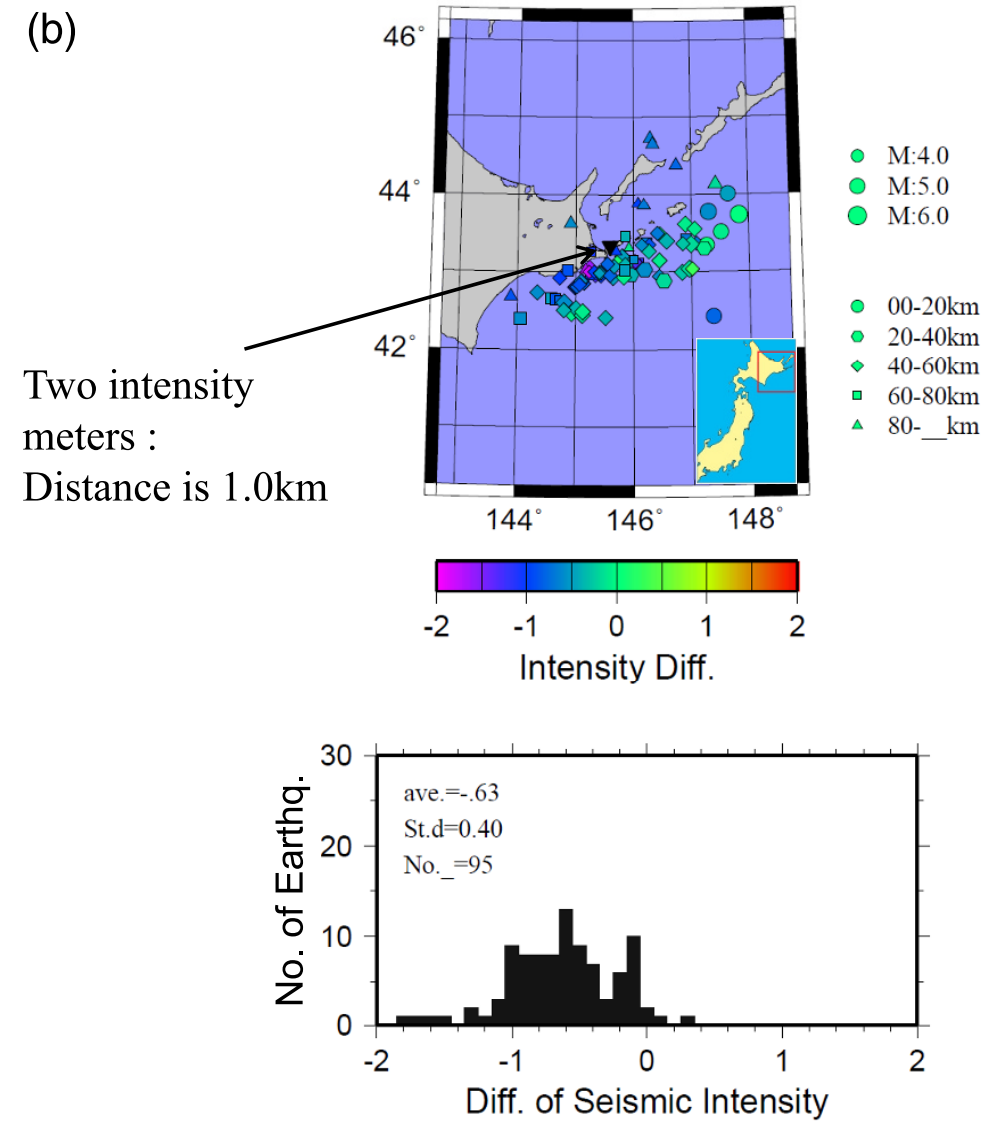

Fig. 10. (a) Intensity differences for earthquakes observed at a pair of adjacent sites in the Kanto region, Japan. Focal depth and magnitude of the earthquakes are represented by different symbol types and their size, respectively. The color represents the intensity difference between the two sites. (b) Intensity difference at a pair of sites in Hokkaido, Japan. 


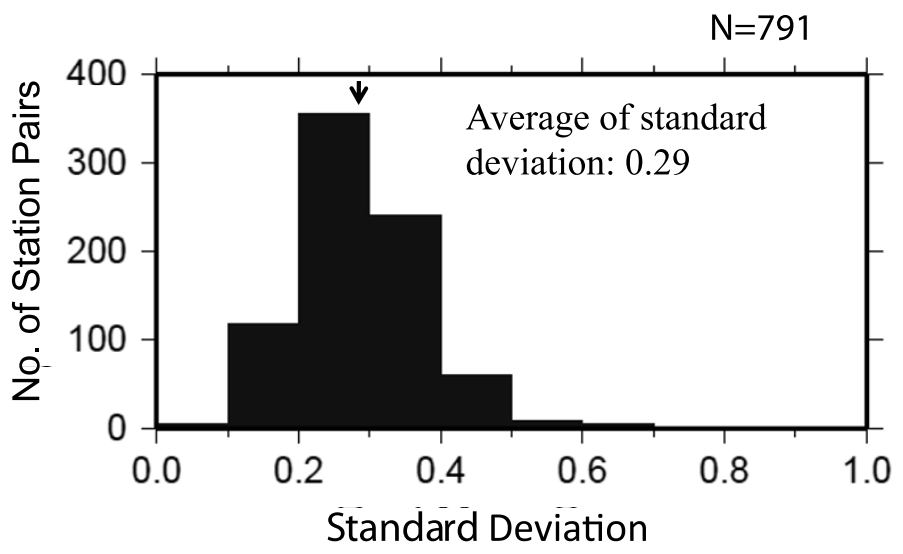

Fig. 11. Histogram of the standard deviation (for example, standard deviation of the site pair of Fig. 10(a) is 0.52 and that of Fig. 10(b) is 0.40 ) of 791 pairs of sites. The average of the standard deviation was 0.29 .

Table 2. Summary of the data selection and estimation of the uncertainty for the anticipation of seismic intensity. The uncertainty due to the source factor is given in A1, A2, and A3 and that due to the site amplification factor is given in B.

\begin{tabular}{|c|c|c|c|c|c|c|c|c|}
\hline & \multicolumn{3}{|c|}{ (1) } & (2) & (3) & (4) & (5) & (6) \\
\hline & \multicolumn{3}{|c|}{ Earthquake Selection } & \multirow{2}{*}{$\begin{array}{c}\text { Station Selection } \\
\text { Distance } \\
\text { between sites }\end{array}$} & \multirow{2}{*}{$\begin{array}{l}\text { Magnitude /site } \\
\text { correction }\end{array}$} & \multirow{2}{*}{$\begin{array}{c}\text { Number of } \\
\text { pairs }\end{array}$} & \multirow{2}{*}{$\begin{array}{l}\text { Uncertainty } \\
\text { (RMS or } \\
\text { Standard } \\
\text { Deviation) }\end{array}$} & \multirow{2}{*}{$\begin{array}{l}\text { For single } \\
\text { earthquake or } \\
\text { single site } \\
(5 / \sqrt{2})\end{array}$} \\
\hline & $\begin{array}{l}\text { Distance } \\
\text { between } \\
\text { epicenters }\end{array}$ & $\begin{array}{c}\text { Difference } \\
\text { of focal } \\
\text { depths }\end{array}$ & $\begin{array}{c}\text { Difference } \\
\text { of Mag. }\end{array}$ & & & & & \\
\hline$\overline{\mathrm{A} 1}$ & $\leq 5 \mathrm{~km}$ & $\leq 5 \mathrm{~km}$ & Same Mag. & - & $\begin{array}{c}\text { Without magnitude } \\
\text { correction }\end{array}$ & 100 & 0.41 & 0.29 \\
\hline A2 & $\leq 5 \mathrm{~km}$ & $\leq 5 \mathrm{~km}$ & Same Mag. & - & $\begin{array}{l}\text { With magnitude } \\
\text { correction }\end{array}$ & 100 & 0.31 & 0.22 \\
\hline A3 & $\leq 5 \mathrm{~km}$ & $\leq 5 \mathrm{~km}$ & $\leq 0.5$ & - & $\begin{array}{l}\text { With magnitude } \\
\text { correction }\end{array}$ & 833 & 0.33 & 0.23 \\
\hline $\mathrm{B}$ & - & - & - & $\leq 5 \mathrm{~km}$ & With site correction & 791 & 0.29 & 0.21 \\
\hline
\end{tabular}

results are summarized in Table 2 . To estimate uncertainty, we compared seismic intensity data recorded at the same observation site from two adjacent earthquakes and data recorded at two adjacent observation sites from the same earthquake. Because we evaluated RMS and the standard deviation of intensity difference from the difference of two earthquakes or two observation sites, it is necessary to divide them by $\sqrt{2}$ for a single earthquake or a single site. For example, because 0.41 was obtained in Section 3.1 as the uncertainty of seismic intensity using the difference of two earthquakes, $0.41 / \sqrt{2} \fallingdotseq 0.29$ is the uncertainty for a single earthquake. Even when the path factor and site amplification factor are appropriately evaluated, we should expect an uncertainty of 0.29 in anticipated seismic intensity if the JMA magnitude is used to specify the source factor, and an uncertainty of $0.22(\fallingdotseq 0.31 / \sqrt{2})$ if the average of intensities is used as the source factor. Even when the source factor and path factor are appropriately evaluated, we should expect errors of $0.21(\fallingdotseq 0.29 / \sqrt{2})$ if the site amplification factor is represented by single scalar value.

The uncertainty of the anticipated seismic intensity in this paper corresponds to the ideal case of the hypocenter and magnitude being determined precisely and path factor being represented using 3D attenuation structure based on Eq. (2). As mentioned above, intensity anticipation in the current JMA EEW system is based on Eq. (1), that is 1D structure, and the estimation of hypocenter and magnitude is performed using only an earlier part of waveforms at a few stations. The uncertainty calculated in this paper is smaller than the error of the current JMA EEW procedure. The uncertainties and errors considered in this paper indicate the intrinsic limit of anticipated seismic intensity in the current JMA EEW procedure, provided that the hypocenter and magnitude are determined precisely. It should be noted here that the uncertainty due to fluctuations of the path factor should also be considered in the calculation of anticipated seismic intensity in addition to the above-mentioned source and site factors.

We have investigated the uncertainties of anticipated seismic intensity base on Eq. (2) when the source factor, $S$, and site factor, $G$, are represented by scalars. However, because they have spectrum contents, $S$ and $G$ (and also path factor $f_{2}$ ) should be represented by the function of frequency. The dominant frequency of seismic waves is different from earthquake to earthquake and also from site to site. Even when the seismic intensity is the same, the dominant frequency may be different. To improve calculations of anticipated seismic intensity for EEW purposes, spectrum information of the source factor and site amplification factor may be effective instead of single scalar values. The prediction of seismic ground motion based on Eq. (1) or Eq. (2) for various frequency bands leads to a more precise prediction and then improves the accuracy of the anticipation of seismic intensity. 
Figure 2(c) suggests that the effect of the rupture directivity is also an important consideration. In Eq. (1) and Eq. (2), the effect of rupture directivity is not taken into account. Introduction of the rupture directivity is expected to be effective for improving the intensity anticipation.

Acknowledgments. The authors thank Prof. T. Kagawa and Dr. S. Horiuchi for their reviews. Their comments were useful for improving the manuscript. The authors also thank Prof. T. Iidaka for his efforts as an editor. The JMA intensity catalog is based on the observations of not only JMA but also municipalities and NIED. The unified hypocenter catalog of JMA includes data from NIED, Hokkaido University, Hirosaki University, Tohoku University, University of Tokyo, Nagoya University, Kyoto University, Kochi University, Kyushu University, Kagoshima University, the National Institute of Advanced Industrial Science Technology, the Tokyo metropolitan government, the Shizuoka prefectural government, the Kanagawa prefectural government, the City of Yokohama, the Japan Marine Science and Technology Center, and JMA. We thank all of these institutions and organizations for their effort in maintaining these observations. Some figures were made using Generic Mapping Tools (Wessel and Smith, 1995).

\section{References}

Alcik, H., O. Ozel, N. Apaydin, and M. Erdik, A study on warning algorithms for Istanbul earthquake early warning system, Geophys. Res. Lett., 36, L00B05, doi:10.1029/2008GL036659, 2009.

Allen, R. M., H. Brown, M. Hellweg, O. Khainovski, P. Lombard, and D. Neuhauser, Real-time earthquake detection and hazard assessment by ElarmS across California, Geophys. Res. Lett., 36, L00B08, doi:10.1029/2008GL036766, 2009.

Atkinson, G. M., Single-station sigma, Bull. Seismol. Soc. Am., 96, 446455, 2006.

Bragato, P. L., Limits for the improvement of ground-motion relations in Europe and the Middle East by accounting for site effects, Bull. Seismol. Soc. Am., 98, 2061-2065, 2008.

Douglas, J. and P. M. Smit, How accurate can strong ground motion attenuation relations be?, Bull. Seismol. Soc. Am., 91, 1917-1923, 2001.

Espinosa Aranda, J. M., A. Jimenez, G. Ibarrola, F. Alcantar, A. Aguilar, M. Inostroza, and S. Maldonado, Mexico City seismic alert system, Seismol. Res. Lett., 66, 42-52, 1995.

Horiuchi, S., H. Negishi, K. Abe, A. Kaminuma, and Y. Fujinawa, An automatic processing system for broadcasting earthquake alarms, Bull. Seismol. Soc. Am., 95, 708-718, 2005.

Hoshiba, M., Fluctuation of wave amplitude even when assuming convolution of source, path and site factors-Effect of rupture directivity-, Phys. Earth Planet. Inter., 137, 45-65, 2003.

Hoshiba, M., O. Kamigaichi, M. Saito, S. Tsukada, and N. Hamada, Earthquake early warning starts nationwide in Japan, Eos Trans. AGU, 89, 73-74, 2008.

Hsiao, N.-C., Y.-M. Wu, T.-C. Shin, L. Zhao, and T.-L. Teng, Development of earthquake early warning system in Taiwan, Geophys. Res. Lett., 36, L00B02, doi:10.1029/2008GL036596, 2009.

Ikeura, T. and S. Noda, Variation of strong motion response spectra observed at the same site-analysis on data from pair events of the same magnitude and the same hypocentral distances-, J. Jpn. Assoc. Earthq.
Eng., 5, 12-30, 2005 (in Japanese).

Japan Meteorological Agency, Seismic Intensity, pp 238, Gyosei, Tokyo, 1996 (in Japanese).

Japan Meteorological Agency, Report of the Mid Niigata prefecture Earthquake in 2004, Tech. Rep. JMA, 127, 1-185, 2005 (in Japanese).

Japan Meteorological Agency, The Seismological and Volocanological Bulletin of Japan for January 2009, Japan Meteorological Agency, 2009.

Kamigaichi, O., JMA earthquake early warning, J. Jpn. Assoc. Earthq. Eng., 4, 134-137, 2004.

Kamigaichi, O., M. Saito, K. Doi, T. Matsumori, S. Tsukada, K. Takeda, T. Shimoyama, K. Nakamura, M. Kiyomoto, and Y. Watanabe, Earthquake Early Warning in Japan-Warning the general public and future prospects-, Seismol. Res. Lett., 80, 717-726, 2009.

Matsuoka, M. and S. Midorikawa, The digital national land information and seismic microzoning, Proceeding of the 22nd Symposium of Earthquake Ground Motion, AIJ, 23-34, 1994 (in Japanese).

Midorikawa, S., K. Fujimoto, and I. Muramatsu, Correlation of new J.M.A instrumental seismic intensity with former J.M.A. seismic intensity and ground motion parameters, J. Inst. Soc. Safety Sci., 51-56, 1999 (in Japanese).

Morikawa, N., T. Kanno, A. Narita, H. Fujiwara, T. Okumura, Y. Fukushima, and A. Guerpinar, Strong motion uncertainty determined from observed records by dense network in Japan, J. Seismol., 12, 529546, 2008.

Nakamura, H., S. Horiuchi, C. Wu, S. Yamamoto, and P. A. Rydelek, Evaluation of the real-time earthquake information system in Japan, Geophys. Res. Lett., 36, doi:10.1029/2008GL036470, 2009.

Odaka, T., K. Ashiya, S. Tsukada, S. Sato, K. Ohtake, and D. Nozaka, A new method of quickly estimating epicentral distance and magnitude from a single seismic record, Bull. Seismol. Soc. Am., 93, 526-532, 2003.

$\mathrm{Si}, \mathrm{H}$. and S. Midorikawa, Attenuation relationships of peak ground acceleration and velocity considering effects of fault type and site condition, J. Struct. Constr. Eng., AIJ, 523, 63-70, 1999 (in Japanese).

Strasser, F. O., N. A. Abrahamson, and J. J. Bommer, Sigma: Issues, insights, and challenges, Seismol. Res. Lett., 80, 40-56, 2009.

Tsukada, S., S. Odaka, K. Ashiya, K. Ohtake, and D. Nozaka, Analysis of the envelope waveform of the initial part of $\mathrm{P}$ waves and its application to quickly estimating the epicentral distance and magnitude, Zisin 2, 56, 351-361, 2004 (in Japanese).

Wessel, P. and W. H. F. Smith, New version of the generic mapping tool released, Eos Trans. AGU, 76, 329, 1995.

Yamamoto, S., S. Horiuchi, H. Nakamura, and C. Wu, Effectiveness of seismic intensity magnitude for earthquake early warning, BUTSURITANSA, 60, 407-417, 2007 (in Japanese).

Yamamoto, S., P. Rydelek, S. Horiuchi, C. Wu, and H. Nakamura, On the estimation of seismic intensity in earthquake early warning systems, Geophys. Res. Lett., 35, L07302, doi10.1029/2007GL033034, 2008.

Zollo, A., G. Iannaccone, M. Lancieri, L. Cantore, V. Convertito, A. Emolo, G. Festa, F. Gallovič, M. Vassallo, C. Martino, C. Satriano, and P. Gasparini, Earthquake early warning system in southern Italy: Methodologies and performance evaluation, Geophys. Res. Lett., 36, L00B07, doi:10.1029/2008GL036689, 2009.

M. Hoshiba (e-mail: mhoshiba@mri-jma.go.jp), K. Ohtake, K. Iwakiri, T. Aketagawa, H. Nakamura, and S. Yamamoto 